\title{
Long-time global radiation for Central Europe derived from ISCCP Dx data
}

\author{
N. Petrenz ${ }^{1}$, M. Sommer ${ }^{1}$, and F. H. Berger ${ }^{1,2}$ \\ ${ }^{1}$ TU Dresden, Fakultaet Forst-, Geo- und Hydrowissenschaften, Fachrichtung Wasserwesen, 01062 Dresden, Germany \\ ${ }^{2}$ German Meteorological Service, Meterological Observatory Lindenberg (FELG), 15848 Tauche/Lindenberg, Germany
}

Received: 4 May 2007 - Published in Atmos. Chem. Phys. Discuss.: 14 June 2007

Revised: 12 September 2007 - Accepted: 21 September 2007 - Published: 28 September 2007

\begin{abstract}
The global Dx dataset of the International Satellite Cloud Climatology Project (ISCCP) with a spatial resolution of about $30 \times 30 \mathrm{~km}^{2}$ was analysed to produce spatially highly resolved long-time datasets to describe the radiation budget for Central Europe over the period of 1984-2000. The computation of shortwave and longwave radiant flux densities at top of atmosphere and at surface was based on 1D radiative transfer simulations. The simulations were carried out for all relevant atmospheric and surface conditions and the results were inserted into a look-up table. Thus, longtime calculations for all conditions and time slices of the Dx dataset could be realised. The study is focussed on the global radiation at surface.

The first examination was carried out for the ISCCP D1 and the ISCCP D2 dataset. These datasets, including cloud and surface information on a different spatial scale $\left(280 \times 280 \mathrm{~km}^{2}\right)$, were applied to the produced look-up table analogue to the Dx data. The calculated global radiation of the D1 and D2 dataset were compared to the Dx dataset. The differences between these datasets mainly range from $5-15 \mathrm{Wm}^{-2}(2-6 \%)$ with regional peaks up to $25 \mathrm{Wm}^{-2}$ $(10 \%)$.
\end{abstract}

The evaluation with the GEWEX Surface Radiation Budget (SRB) data emphasises differences between $5-25 \mathrm{Wm}^{-2}$ (6-16\%) over land areas. Deviations to an ISCCP provided flux data set vary from $0 \mathrm{Wm}^{-2}$ in the North up to $35 \mathrm{Wm}^{-2}$ $(0-13 \%)$ in the South of Central Europe.

The global radiation datasets provided by the Global Energy Balance Archive (GEBA) and the German Meteorological Service (DWD) agree well, but they are $5-25 \mathrm{Wm}^{-2}(7-$ $10 \%)$ lower than the Dx results.

Annual analyses of global radiation of various regional climate models complete the study. It is figured out that the used models and methods reveal a couple of discrepancies.

Correspondence to: N. Petrenz

(nadja.petrenz@forst.tu-dresden.de)
Especially in wintertime the results of our analysis differ to the considered models. Principally the uncertainties were caused by the determined range of values and simplifications for the computation of the radiative transfer simulation.

\section{Introduction}

The knowledge of incoming and outgoing shortwave and longwave radiant flux densities provides the key information for the net balance and thus for energy exchanges between atmosphere and surface. Therefore it is necessary to infer these radiant flux densities as accurately as possible to realise a correct characterisation of the Earth's climate system (Hollmann et al., 2006). The radiation budget is object of investigation in numerous studies, which infer radiant flux densities at top of atmosphere (TOA) and at surface using ground based measurements or remotely sensed data (Raschke et al., 2005, 2006).

Among others the Global Energy Balance Archive (GEBA/Gilgen et al., 1997; Gilgen and Ohmura, 1999), the Baseline Surface Radiation Network (BSRN/Ohmura et al., 1998), the Atmospheric Radiation Measurement (ARM/Stokes and Schwartz, 1994) or the Surface Radiation Budget Network (SURFRAD/Augustine et al., 2000) provide high quality datasets from surface observation sites with directly measured radiant flux densities. Due to the point measurements spatial interpolations are ambiguous and mostly less representative because of the wide distances between the stations within meteorological networks. Remote sensing systems collect radiative properties and surface temperatures at different temporal and spatial scales allowing the derivation of area-integrated radiances and radiant flux densities at different atmospheric layers. In this regard the global datasets of the Earth Radiation Budget Experiment (ERBE/Barkstrom et al., 1989), the International Satellite Cloud Climatology Project (ISCCP/Schiffer and Rossow,

Published by Copernicus Publications on behalf of the European Geosciences Union. 
Table 1. Summary of the used ISCCP data products according to Rossow et al. (1996).

\begin{tabular}{|c|c|c|c|c|c|}
\hline Dataset & Temporal Resolution & Spatial Resolution & Parameters & & \\
\hline & & & Cloud & Surface & Other \\
\hline ISCCP Dx & 3-hourly & ca. $30 \times 30 \mathrm{~km}^{2}$ & $\begin{array}{l}\text { - cloud top temperature } \\
\text { - cloud top pressure } \\
\text { - optical thickness }\end{array}$ & $\begin{array}{l}\text { - (clear sky) surface temperature } \\
\text { - land/water/ near shore flag } \\
\text { - snow/ice code }\end{array}$ & $\begin{array}{l}\text { - latitude, longitude } \\
\text { - solar zenith angle } \\
\text { - day/night flag }\end{array}$ \\
\hline ISCCP D1 & 3-hourly & ca. $280 \times 280 \mathrm{~km}^{2}$ & $\begin{array}{l}\text { - cloud top temperature } \\
\text { - cloud top pressure } \\
\text { - optical thickness }\end{array}$ & $\begin{array}{l}\text { - (clear sky) surface temperature } \\
\text { - land/water cover } \\
\text { - snow/ice cover }\end{array}$ & $\begin{array}{l}\text { - latitude, longitude } \\
\text { - solar zenith angle } \\
\text { - day/night }\end{array}$ \\
\hline ISCCP D2 & 3-hourly monthly means & ca. $280 \times 280 \mathrm{~km}^{2}$ & $\begin{array}{l}\text { - cloud top temperature } \\
\text { - cloud top pressure } \\
\text { - optical thickness }\end{array}$ & $\begin{array}{l}\text { - surface temperature } \\
\text { - land/water cover } \\
\text { - snow/ice cover }\end{array}$ & - latitude, longitude \\
\hline
\end{tabular}

1983), the Clouds and the Earth's Radiant Energy System (CERES/Wielicki et al., 1998) or the GEWEX Surface Radiation Budget (SRB/Stackhouse et al., 2000) are often applied. Estimations of shortwave and longwave surface radiation fluxes from satellite measurements are carried out with specially developed algorithms consisting of simple parameterisations concerning cloud physics, atmosphere and aerosols (Darnell et al., 1988, 1992; Gupta et al., 1992; Pinker and Laszlo, 1992; Pinker et al., 1995; Rossow and Zhang, 1995; Zhang et al., 1995). The evaluation of calculated radiative flux components is complicated since the parameterisation of atmospheric and surface properties is still problematic in model approaches.

The decisive input to the climate system is the incoming solar radiation, which is nearly con-stant at TOA. Incoming solar radiation is attenuated by the atmosphere and the description of this process of radiative transfer is treated differently by the available transfer codes. Further investigations regarding other radiation budget components assume an exact determination of the sum of direct and diffuse incoming solar radiation (global radiation). This paper describes and discusses a specially developed method for calculating radiation budget components at TOA and at surface using various ISCCP data. Detailed analyses and comparisons for the global radiation are shown.

\section{Input data and method description}

\subsection{Data source}

The ISCCP datasets with a current availability from July 1983 to December 2004 are used to compute the shortwave and longwave radiant flux components for both TOA and surface. At present three datasets (Dx/D1/D2) exist combining data of all available geostationary and polar orbit weather satellites (Rossow et al., 1996; Rossow and Schiffer, 1999). The datasets build up on each other (D1 on Dx and D2 on D1) and include a nearly complete global information of var- ious cloud properties. Table 1 gives a summery of the spatial and temporal resolution of the datasets as well as the used parameters.

Additionally the weekly snow/ice cover data from the NOAA/National Environmental Satellite Data and Information Service (NESDIS) and from the NAVY/NOAA Joint Ice Center (see Rossow et al., 1991) are enclosed.

As reference the three-hourly ISCCP Dx data with a spatial sampling resolution of approx. $30 \times 30 \mathrm{~km}^{2}$, one random pixel of 4-7 km without specific knowledge of location is characteristic for the whole grid cell, is used. ISCCP D1 and D2 are datasets with an equal area grid of approx. $280 \times 280 \mathrm{~km}^{2}\left(2.5^{\circ} \times 2.5^{\circ}\right.$ at the equator $)$, but with different temporal sampling intervals. Thus the D1 dataset provides three-hourly cloud information and the D2 dataset is statistically averaged to three-hourly monthly means (see more details in Rossow et al., 1996).

All calculations are carried out over the period of 1984-2000 (17 years) covering a region of $65^{\circ} \mathrm{N} / 35^{\circ} \mathrm{E} / 30^{\circ} \mathrm{S} / 15^{\circ} \mathrm{W}$ (henceforth Central Europe). In the run-up to radiative transfer simulations gaps, plausibility and spatial structures for each dataset are tested. The global D1 and D2 time series of cloud amount and surface temperature have only few gaps $(<0.2 \%)$. Due to the method creating the equal-area grid cells uncertainties in spatial structures are possible. But the analysis exhibited logical spatial structures. In contrast the gaps of parameters, which are estimated only during the day, like optical thickness, cloud type and reflectivity, are more extensive (approx. 5.0\%) and cause uncertainties for further computations. Furthermore at the edge of the geostationary satellite images the data are either missing or of insufficient quality.

In Fig. 1a the mean global cloud amount of the D1 dataset over the whole period is shown in context with the calculated temporal trends. To avoid the influences of seasonal variations annual means are produced and applied to the trend analysis. A clear negative trend in the cloud amount of about $2.5 \%$ over wide areas with regional peaks of $15.0 \%$ and more is observed. To verify the detected trends the non-parametric 

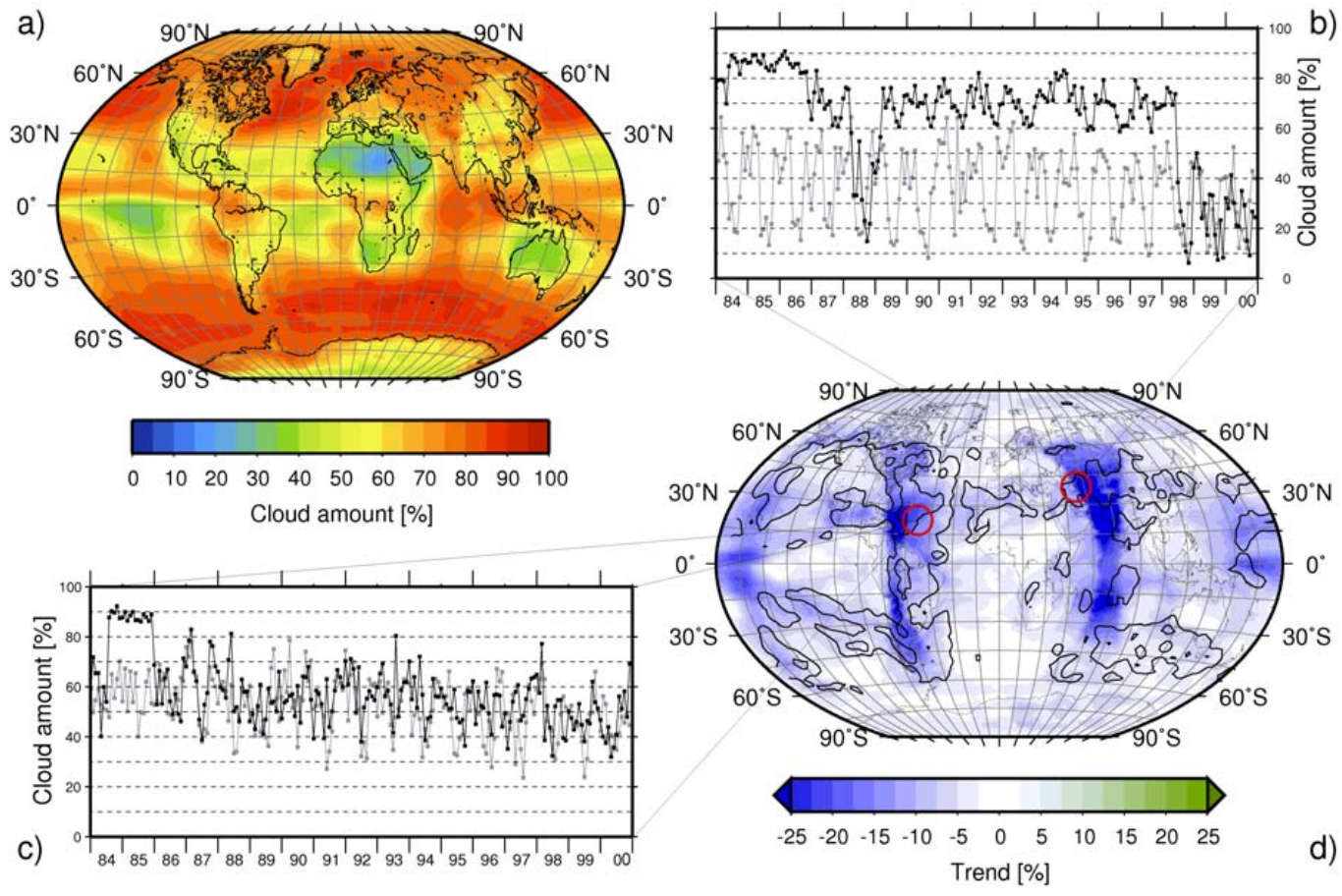

Fig. 1. Mean global ISCCP D1 cloud amount. (a) Annual mean over the period of 1984-2000. (d) Temporal variances of cloud amount as well as statistically firmed trends within black contoured regions over the periods of 1984-2000. (b), (c) Obvious inhomogeneities of time series in two special regions (inhomogeneous time series are black, homogeneous time series are grey).

Mann-Kendall test - applicable in case of non-linear trends - is used (Rapp, 2000):

$Q=\frac{\sum_{i=1}^{N-1} \sum_{j=i+1}^{N} \operatorname{sgn}\left(y_{j}-y_{i}\right)}{\sqrt{\frac{1}{18}[N(N-1)(2 N+5)]}}$

where $Q$ is the numerical test value, $N$ is the length of the time series, sgn describes the lead-ing sign, $y_{i}$ and $y_{j}$ are the values to compare. The test only rates the relative increase or decrease of the values but provides no detailed information of time dependent changes. The corresponding confidence interval $V$ and the probability value $\alpha$ to every calculated $Q$ are taken from Rapp (2000). In Fig. 1 the visible global trends are only significant within the contoured regions exhibiting a confidence interval of $V>99.7 \%$. At the edge of the geostationary satellite images the largest negative trends occur which are also statistically firmed. Evaluating these trends the time series of two joining pixel in two different areas are investigated (red circles).

Figure 1c reveals the inhomogenities over the period of August 1984 to December 1985 (black graph). Long-term measurement gaps of the operational geostationary satellite GOES-East were discovered that intensify these trends. The black graph in Fig. 1b represents a pixel that belongs to the disk recorded by the geostationary satellite INSAT. The data of this satellite only exist for the period of April 1988 to March 1989. Due to this huge failure only the data of polar orbit satellites were available twice per day therefore providing insufficient measurements. At the beginning of 1998 Meteosat- 5 has been replaced to the position $63^{\circ}$ East to compensate for the full disk of INSAT resulting in consistent time series. Regarding to these analyses the observed and assured trends within the critical regions are adulterated. For Central Europe only Meteosat data are used. There no profoundly long-term gaps and failures could be located. Similar analyses relating to inhomogeneities in the time series of the ISCCP dataset are documented in Evan et al. (2007).

The used ISCCP Dx dataset includes pixel level cloud information that is primarily based on the information of the cloud mask ( 1 = clouds; $0=$ no clouds $)$ and on relevant information of cloud top temperature, cloud top pressure and cloud optical thickness. With these parameters a classification of cloud classes and cloud layers according to Rossow et al. (1996) is carried out. 15 cloud classes and three cloud layers could be determined and the frequencies of each are calculated.

\subsection{Radiative Transfer Model (RTM) and method}

The computations are carried out with the complex 1D RTM Streamer, that calculates radiances and radiant flux densities at each atmospheric level for several atmospheric 

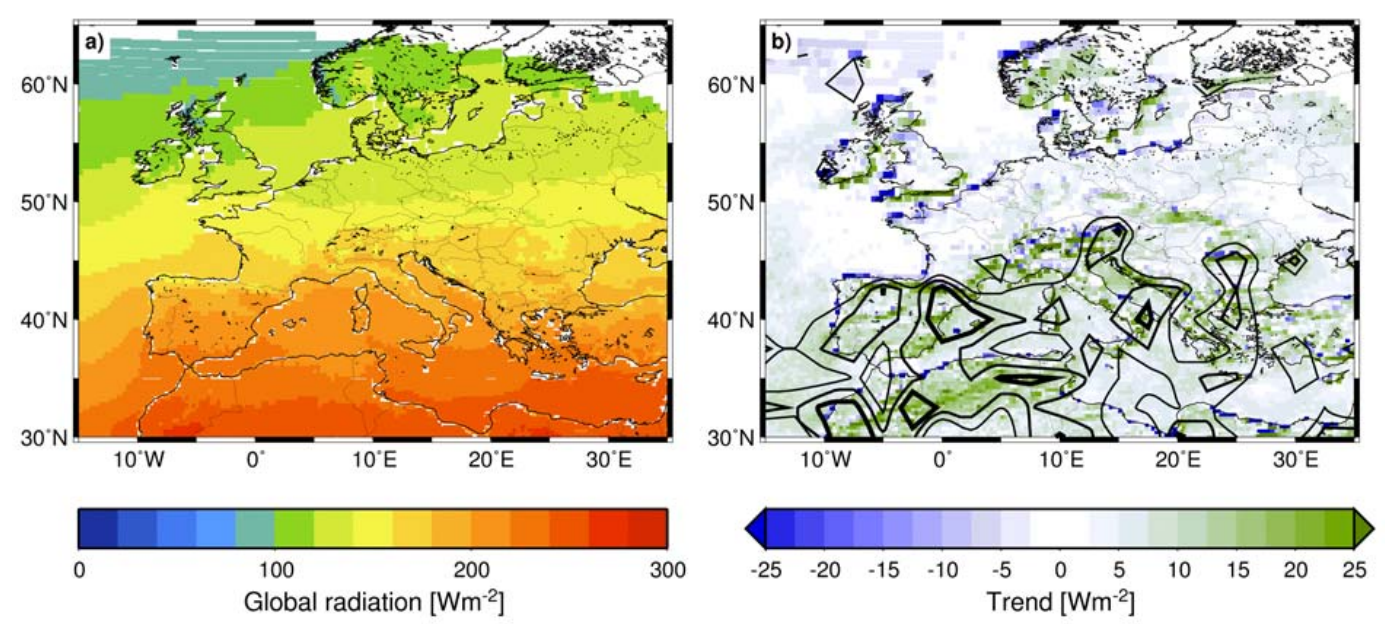

Fig. 2. Global radiation at surface based on ISCCP Dx data. (a) Annual mean over the period of 1984-2000, (b) Temporal trend over the period of 1984-2000 with areas of statistical significance (black contoured).

and surface conditions (Key, 2001; version 3.0 beta 7). The solution of the radiative transfer equation can be realized for a horizontal plane-parallel atmosphere with the Delta-2-Stream-Approximation (Toon et al., 1989) and the Discrete-Ordinate-Method (DISORT) according to Stamnes et al. (1988). To estimate shortwave $(0.28-4.0 \mu \mathrm{m})$ and longwave $(4.0-500.0 \mu \mathrm{m})$ radiant flux densities at different layers special input parameters are required regarding clouds, their geometrical, optical and microphysical properties as well as surface and atmospheric properties. First calculations are carried out for the monthly D2 dataset at 12:00 UTC. For that purpose the input parameters are taken directly from the dataset except information concerning the microphysics of clouds. The microphysical cloud parameters, like Liquid/Ice Water Content (LWC/IWC) and effective radius $r_{e}$, are defined according to Polar Radiation Fluxes from ISCCP (PRFI, 2000). Thus LWC is $0.2 \mathrm{gm}^{-3}$ and $r_{e}$ is $10 \mu \mathrm{m}$ for water clouds and IWC is $0.07 \mathrm{gm}^{-3}$ and $r_{e}$ is $30 \mu \mathrm{m}$ for ice clouds. Atmospheric and aerosol standard profiles from surface $(0 \mathrm{~km})$ up to TOA $(100 \mathrm{~km})$ are specified within the model. The different vegetation types of the $\mathrm{D}$ datasets are adapted to the vegetation types defined in the RTM Streamer followed by the internal modulation of reflectivity.

To handle radiative transfer computations for all ISCCP D datasets and all radiation budget components for the period of 1984-2000 (17 years) look-up tables are an useful instrument. Hence relevant nodes of all individual model input parameters are defined and radiative transfer computations are carried out for all expedient input parameter combinations. The resulting shortwave and longwave radiant flux densities with their appropriate parameter sets are tabulated. Now for every individual input parameter set of each grid cell at each time slice the corresponding radiant flux densities can be derived using multidimensional linear interpolations between the parameter increments.

\section{Results}

\subsection{Comparison with other satellite derived data products}

The computed and altitude corrected global radiation at surface over the period of 1984-2000 is based on the highly resolved ISCCP Dx dataset and is shown in Fig. 2 for Central Europe. There the distinctive North-South gradient with values of about $75 \mathrm{Wm}^{-2}$ in the North and maxima of $300 \mathrm{Wm}^{-2}$ in the South of the investigation area is shown in Fig. 2a. Data gaps along the coastlines are displayed in white. Due to the solely usage of Meteosat data the covered area is limited to the scanned disk so less values above ca. $60^{\circ}$ latitude exist. Figure $2 \mathrm{~b}$ shows the temporal variability of global radiation for the 17 years examined. A statistically firmed increase of global radiation $\left(10-20 \mathrm{Wm}^{-2}\right)$ in the South of the target area is distinguished. The strong contours indicate regions with a confidence interval $>99.7 \%$ and fine contours assign a confidence interval of $>90.0-95.0 \%$. Positive and negative trends are detected in the remaining Central Europe as well, but they could not be certified.

Additionally the global radiation for the ISCCP D1 and ISCCP D2 datasets was computed using the same look-up table as for the Dx dataset in order to provide a common basis for comparisons between the three datasets. Due to their different temporal and spatial resolutions the datasets are adapted and upscaled to the resolution of the D2 dataset (monthly means, $280 \times 280 \mathrm{~km}^{2}$ ). Figure 3 shows that over wide areas the radiant flux densities of the D1 dataset are approx. $10-15 \mathrm{Wm}^{-2}$ lower than the Dx dataset, except for the most southern area where differences increase up to 20$30 \mathrm{Wm}^{-2}$. In contrast deviations between the Dx and the D2 dataset only appear in few regions, most notably in alpine regions and in North Africa. Thus values up to $\pm 25 \mathrm{Wm}^{-2}$ in comparison to the Dx dataset can be observed. Considerable 


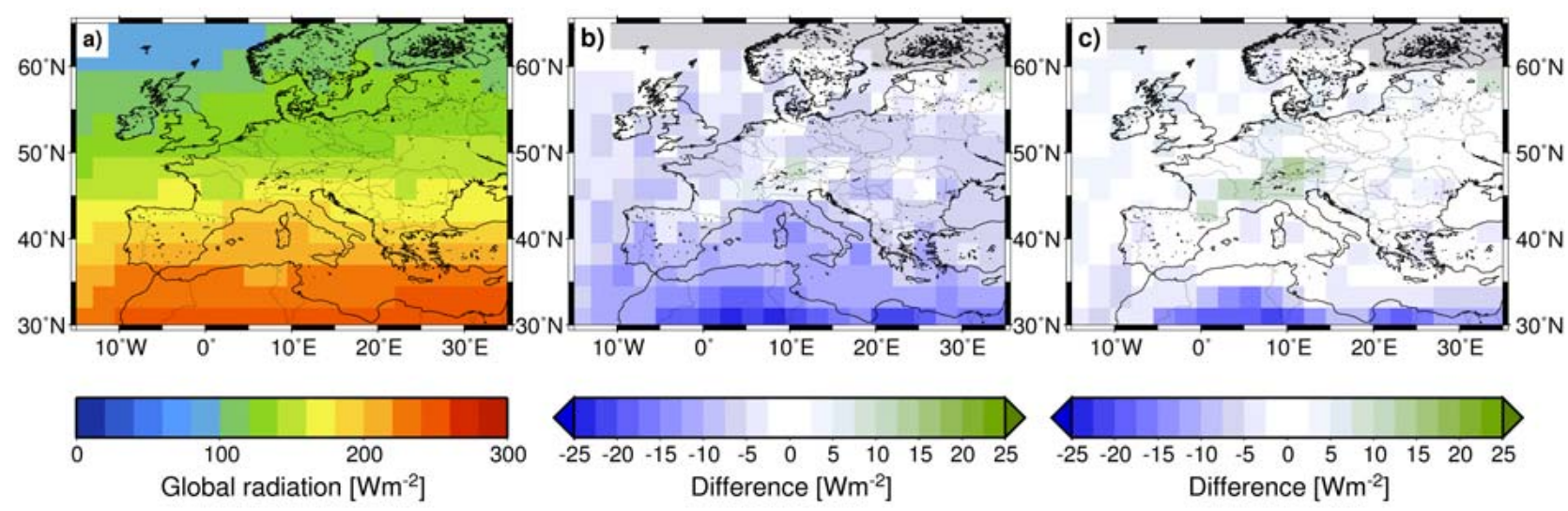

Fig. 3. Comparison of calculated global radiation at surface over the period of 1984-2000. (a) ISCCP Dx dataset (reference) and the appropriate differences to the ISCCP D1 dataset (b: D1-Dx) as well as to the ISCCP D2 dataset (c: D2-Dx).

discrepancies to the Dx dataset are detected for higher altitudes (Alps) with higher values and for arid environment (North Africa) with lower values for the D1 and D2 dataset. That suggests possible uncertainties in altitude correction and in atmospheric and subjacent surface parameterisation. Given the identical analysis the deviations between the ISCCP D datasets using same method indicate that after adapting to the comparable resolution the parameters of the origin datasets from Dx over D1 to D2 differ considerably. The differences at northern latitudes above $60^{\circ}$ are not relevant due to the insufficient Dx data quality as above mentioned.

For verification of the Streamer results the satellite data products of the GEWEX SRB and the ISCCP FD (Rossow and Zhang, 1995) dataset are applied. Both datasets include monthly shortwave and longwave radiant flux densities at TOA and at surface, but on different spatial resolutions. Thus radiative transfer computations for the SRB long time series are carried out on a $1^{\circ} \times 1^{\circ}$ global grid on the basis of satellite derived cloud data from the ISCCP Dx dataset. The ISCCP FD data depend on cloud information of the ISCCP D1 dataset on a $2.5^{\circ} \times 2.5^{\circ}$ grid.

Hence for comparison the ISCCP Dx and the SRB data are modified and projected onto a grid equivalent to the spatial resolution of the ISCCP FD dataset. The investigation period is $1984-1993$ (10 years).

Figure $4(\mathrm{~b}, \mathrm{c})$ clearly presents a $25 \mathrm{Wm}^{-2}$ higher Dx global radiation at surface for nearly whole Central Europe compared to SRB and ISCCP FD. In North Africa even values up to $45 \mathrm{Wm}^{-2}$ are achieved.

Considerable differences compared to the SRB dataset mainly exist for land surfaces suggesting some assumptions in our used method. In this context analyses regarding the surface albedo are carried out by varying the reference albedo of grassland $(0.225 \pm 0.1)$. This results in global radiation variations of $\pm 5-10 \mathrm{Wm}^{-2}$ (5-8\%), especially with increasing optical thickness. Additional intensifications are ob- served over snow, where uncertainties of 10-20\% in global radiation could be determined.

The impact of clouds on global radiation is without controversy. Therefore the detection of clouds in special developed algorithms is a decisive factor for the quality of the data basis. Over water surfaces clouds could be detected well, but over land surfaces it is difficult in many cases. Thus uncertainties due to land surface heterogeneities could occur. Furthermore cloud radiative forcing and absorption of solar radiation by clouds might be underestimated in the used radiative transfer model (Li, 1995; Cess et al., 1995) which leads to the higher values in global radiation just like a to transparent cloud-free atmosphere.

Additional uncertainties are based on our computations processed using the standardised aerosol profile included in Streamer (aerosol profile of rural areas) with constant aerosol content over the investigated time period. An adaptation to altered conditions within the analysed time series is planned for future studies. The effects of changing aerosol content on global radiation in cloud-free atmospheres are discussed in Wild and Liepert (1998). There the included aerosol effect caused a mean decrease of $18 \mathrm{Wm}^{-2}$ in global radiation at seven German sites.

Another reason for discrepancies could be the altitude correction applied to the global radiation. Our correction method seems to overestimate the global radiation in mountainous regions noticeable in comparison to the SRB data.

The differences to the ISCCP FD dataset are between 5$20 \mathrm{Wm}^{-2}$. They are distributed over the whole area showing a slight North-South gradient with maxima of $35 \mathrm{Wm}^{-2}$ especially over the Mediterranean. These differences were further analysed for special regions, for seasonal cycle as well as the dependence on latitude or longitude within the seasonal cycle, but no sufficient explanation could be found.

Raschke et al. (2006) compared the SRB and ISCCP FD Data and emphasised uncertainties of -3 to $7 \mathrm{Wm}^{-2}$ 


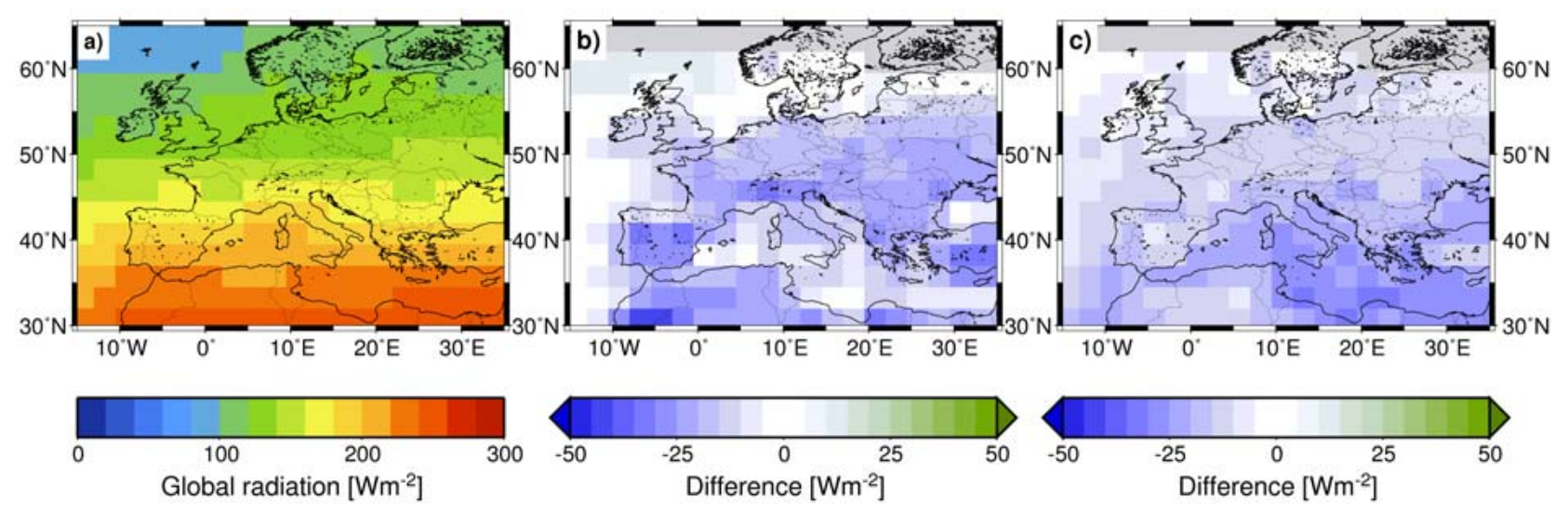

Fig. 4. Comparison of calculated global radiation at surface over the period of 1984-1993; (a) ISCCP Dx dataset (reference) and the appropriate differences to the GEWEX SRB dataset (b: SRB-Dx) as well as to the ISCCP FD dataset (c: FD-Dx).
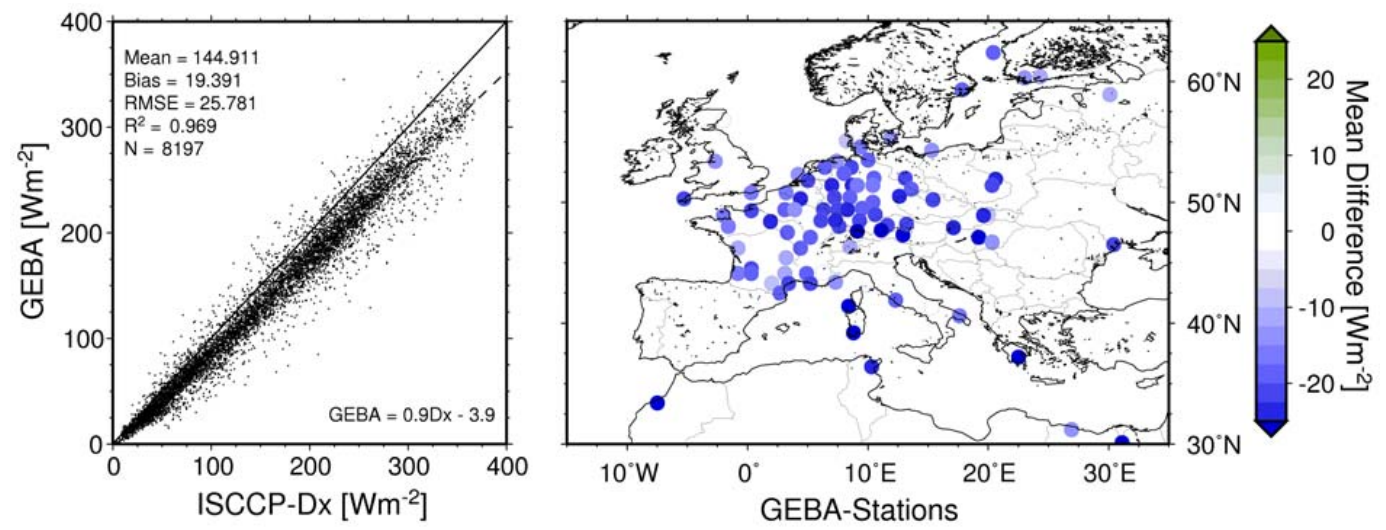

Fig. 5. Monthly global radiation at surface over the period of 1984-1990 for the ISCCP Dx data in comparison with all available GEBAStations of Central Europe (left) and the mean difference at each station between the Dx and GEBA data (right, GEBA-Dx).

in global radiation between $30^{\circ} \mathrm{N}$ and $60^{\circ} \mathrm{N}$ between the datasets due to different initial input data (different total solar irradiance, sun angles above horizon, ancillary data from other sources) and different radiative transfer codes.

\subsection{Evaluation with surface measurements}

For comparisons with surface measurements data of the Global Energy Balance Archive (GEBA) and the German Meteorological Service (DWD) are used. The analyses are based on different periods and regions. While the monthly GEBA data are actually available online from January 1983 until December 1990 for 305 stations in Central Europe, the data of the DWD stations exist for the complete investigation period but only for Germany. To evaluate the comparison between satellite derived radiant flux densities and surface measurements complete years and time series are used. Thus the investigation period for the GEBA dataset is 1984 to 1990 (98 Stations, 28 within Germany) and for the DWD dataset the periods are 1984 to 1990 (28 Stations regarding to GEBA) and 1984-2000 (34 Stations).

The results are statistically analysed and presented in Fig. 5. The scatterplot (Fig. 5, left) reflects a good agreement for the global radiation at surface derived from ISCCP Dx data and the values directly measured at the GEBA stations within the corresponding ISCCP Dx pixel $\left(30 \times 30 \mathrm{~km}^{2}\right)$. But with increasing global radiation values an increase in scattering is visible. The included statistics for the two datasets reveals that over the whole investigation period the RMSE is $25.8 \mathrm{Wm}^{-2}$ and the bias is about $19.4 \mathrm{Wm}^{-2}$. Thus, the values of the ISCCP-Dx pixel are on the average 10\% higher than the values directly measured at the ground stations also mirrored in the equation for the best linear fit. The differences range from $5-25 \mathrm{Wm}^{-2}$.

Other investigations are carried out for Germany using the data of the DWD and GEBA. The scatterplot in Fig. 6 illustrates that the Dx global radiation and the DWD global radiation match well, but the Dx data are approx. $12 \%$ higher 

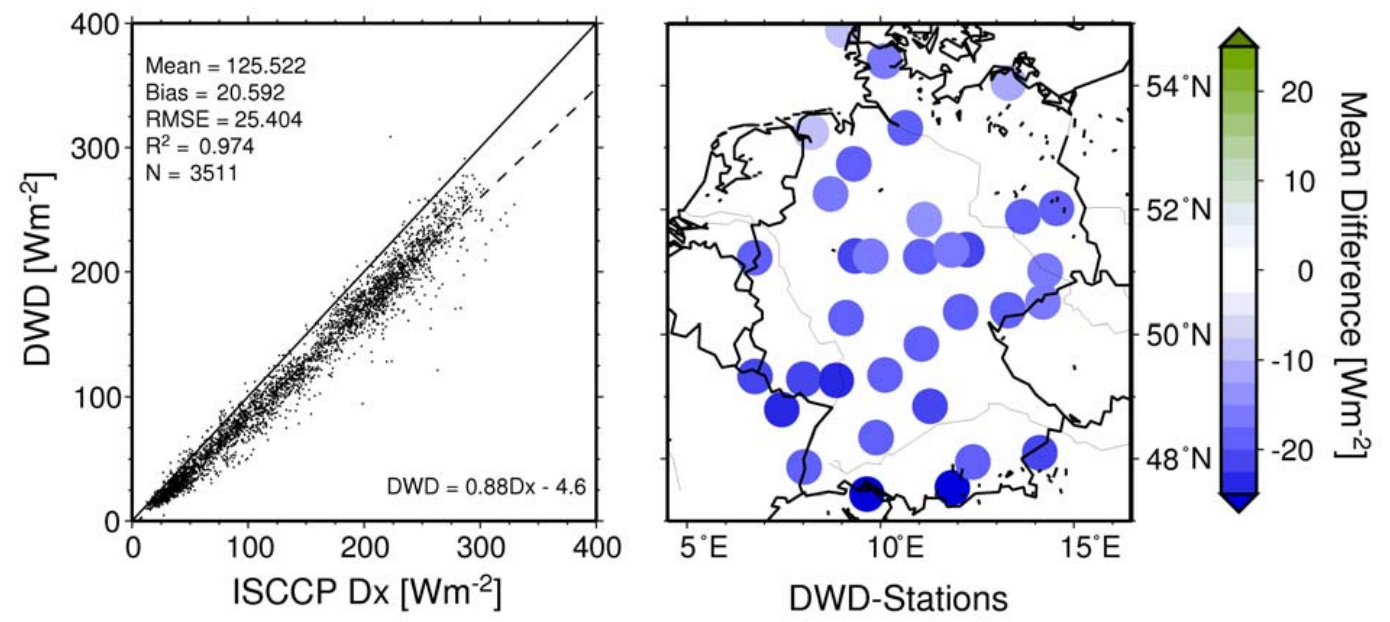

Fig. 6. Monthly global radiation at surface over the period of 1984-1990 for the ISCCP Dx data in comparison with the DWD data of all available gauging stations within the meteorological network of Germany (left) and the mean differences at each station between the Dx and DWD data (right, DWD-Dx).

than the DWD data. Outliers are mainly observed for the ISCCP Dx data with tendency to be higher than the pyranometer measurements. The RMSE and the bias between the two datasets are $25.4 \mathrm{Wm}^{-2}$ and about $20.6 \mathrm{Wm}^{-2}$ respectively. At the individual stations differences from $10-25 \mathrm{Wm}^{-2} \mathrm{oc}-$ cur.

Analyses regarding observation site measurements of GEBA and DWD show only minor deviations between the datasets. As expected the surface measurements agree and it is assumed that the surface sites of GEBA and DWD are the same.

Among the potential reasons for deviations between satellite data and surface measurements, like coarse atmospheric parameterisation within Streamer or changing aerosol contents (Garrat, 1994), the target comparison between a point measurement and an area of $30 \times 30 \mathrm{~km}^{2}$ is one of the most effective due to land surface heterogeneity. The individual pixels within this section have a resolution of $4-7 \mathrm{~km}$. For each time slice one random pixel is used to describe the condition of the whole area. Suboptimal case is that every time an other pixel is chosen to represent a Dx grid cell. Another problem are the radiances determined onboard satellites and in situ because of the different spectral channels of the radiometers. Philipona (2002) assumes in his investigations that unconditioned pyranometer measurements in the past systematically underestimate downward shortwave radiant flux density. After an appropriate correction an approximation of measured and modelled data could be achieved. Generally the uncertainties of surface measurements should be taken into account for validation.

Completing the survey of surface measurements the annual means of global radiation over Germany calculated using the directly measured DWD data (Germany-DWD) and the corresponding ISCCP Dx pixel data (Germany-Dx) over the whole investigation period are compared and analyses of trends are carried out (Fig. 7). Apart from an average difference of $25 \mathrm{Wm}^{-2}$ between the two datasets like above mentioned there is a slightly positive trend $<1.4 \mathrm{Wm}^{-2}$ for the Germany-Dx data but a strong positive trend for the Germany-DWD data of $9.1 \mathrm{Wm}^{-2}$ (Fig. 7a) over the period of 1984-2000. The increase of global radiation at various surface observation sites not only in Germany but also in Eastern and Central Europe since 1990 is also documented as "brightening" in Wild et al. (2005). Potential reason for the weaker increase of Germany-Dx data might be the neglected changes of aerosols absorbing solar radiation over the investigation period above mentioned. Considered separately for each station Fig. 7 (b, c) exhibits irregular positive and negative trends for Germany-Dx and strong positive trends for most Germany-DWD data. Statistically firmed (red circles) is the trend of $10 \mathrm{Wm}^{-2}$ of only one Germany-Dx station (Fig. 7b) but there are a number of stations with significant trends for Germany-DWD data. Their trends range between 2 and $20 \mathrm{Wm}^{-2}$. However, it is conspicuously that the firmed station of Germany-Dx is not proved for Germany-DWD.

\subsection{Comparison with model data}

A further comparison refers to the results of the regional climate models of the respective partners within the project Quantification of Uncertainties In Regional Climate and Climate Change Simulations (QUIRCS). The mesoscale hydrostatic Regional Model (REMO, Jacob and Podzun, 1997; Jacob, 2001) and the non-hydrostatic Meteorological Model (MM5, Grell et al., 1995, 2000) are applied. REMO is used by the BTU Cottbus (BTU, REMO 5.0) as well as by the MPI Hamburg (MPI, REMO 5.1) and MM5 is used by the IMK Karlsruhe. These models operate on a different spatial 

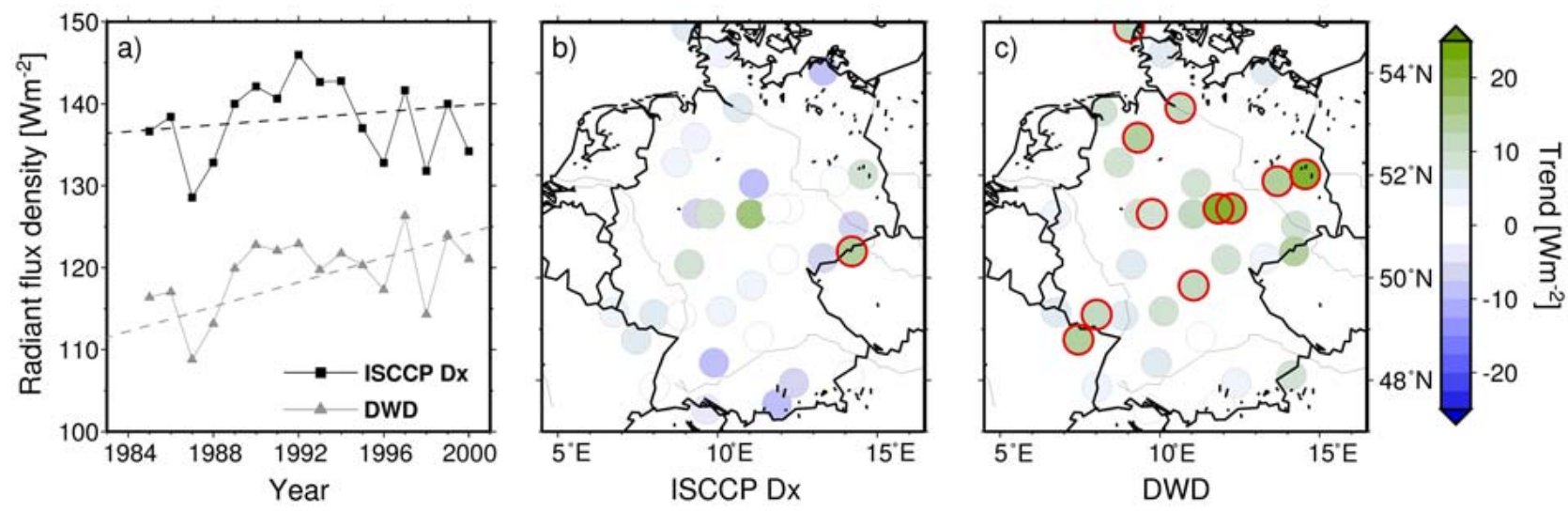

Fig. 7. (a) Annual station means of global radiation at surface over the period of 1984-2000 for the ISCCP Dx data and the DWD data of all available gauging stations within the meteorological network of Germany, (b), (c) temporal trends over the period of 1984-2000 with statistical significant stations (red circles).
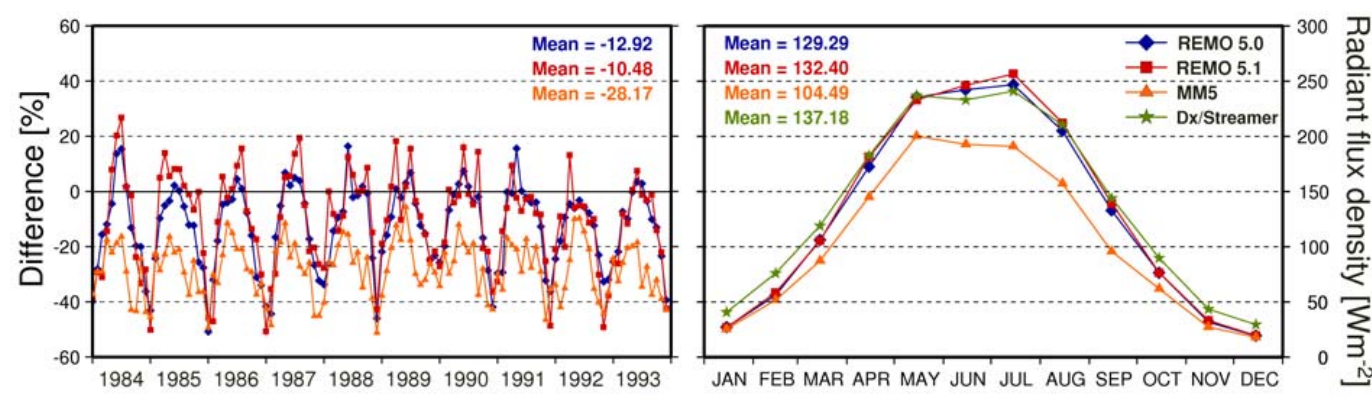

Fig. 8. Monthly differences of global radiation at surface over Germany between the ISCCP Dx data and the results of the regional climate models of the project partners (left: model-Dx) in comparison with the monthly means (right: REMO 5.0 - BTU, blue; REMO 5.1 - MPI, red; MM5 - IFU, orange; Dx/Streamer, green) over the period of 1984-1993.

scale. Hence our results were adapted to the particular available $1 / 6^{\circ}$ grid $(18 \mathrm{~km})$ of the models. The investigation period of project QUIRCS is 1979-1993 (15 years). Due to the availability of ISCCP D data starting in July 1983 the investigation period is limited to 1984-1993 (10 years). Figure 8 (left) plots the differences of monthly global radiation at surface for Germany simulated by regional climate models with respect to our calculated results.

In summertime the REMO output and our results agree well with mean differences of approx. -2 to $4 \mathrm{Wm}^{-2}(-1$ to $2 \%$ ) but in wintertime there are stronger discrepancies between all datasets. Hence the mean annual cycles are examined (Fig. 8, right) and show clearly that our computed global radiation is nearly conform to the results of REMO within the summer months. In winter our results differ on the average $16 \mathrm{Wm}^{-2}$ (27\%) from the model results. Largest deviations are registered compared to the non-hydrostatic model. The MM5 output is obviously lower, on average $30 \mathrm{Wm}^{-2}$ (28\%). Wild et al. (1995) explain the problem of overestimation of global radiation over continents in many climate models amongst others due to an excessive summer dryness.
Hence the good agreement to the REMO results in summertime might also denote an overestimation of the REMO global radiation. Accordingly the humidity in our method seems to be to low and have to be modified.

Detailed analyses for the three German regions Schleswig, Lindenberg and Stuttgart each defined by 49 grid cells show similar results. In Fig. 9 the global radiation at surface with reference to our results (Streamer) is demonstrated. The tenyear means of all models for eve-ry region are given in Fig. 9 (right). It becomes obvious that the pattern for each station is always the same, only the range of values is different. Thus our results are all the time the highest and the results of the MM5 are permanent smaller than the remaining model results. Additionally the dependence on the natural North-South gradient of the global radiation is visible. The scatter plot (Fig. 9, left) shows good agreement between Streamer and REMO 5.0 for all stations with a mean RMSE of $15.9 \mathrm{Wm}^{-2}$. Larger variances appear between Streamer and REMO 5.1 as well as for Streamer and MM5. Complete results are shown in Table 2. 
Table 2. Summary of statistical values of global radiation at surface with reference to the TUD dataset based on the ISCCP Dx data and the RTM Streamer (S) in comparison to the results of the regional climate models REMO 5.0 (BTU), REMO 5.1 (MPI), MM5 (IFU) for the German regions Schleswig, Lindenberg and Stuttgart over the period of 1984-1993.

\begin{tabular}{|c|c|c|c|c|c|c|c|c|c|}
\hline & Schleswig & & & Lindenberg & & & Stuttgart & & \\
\hline & S-REMO 5.0 & S-REMO 5.1 & S-MM5 & S-REMO 5.0 & S-REMO 5.1 & S-MM5 & S-REMO 5.0 & S-REMO 5.1 & S-MM5 \\
\hline Mean $\left[\mathrm{Wm}^{-2}\right]$ & 121.5 & 122.2 & 106.5 & 130.7 & 132.4 & 117.1 & 142.9 & 144.7 & 133.4 \\
\hline Bias $\left[\mathrm{Wm}^{-2}\right]$ & 8.2 & 4.8 & 35.4 & 8.5 & 7.2 & 38.5 & 8.5 & 5.0 & 27.6 \\
\hline RMSE $\left[\mathrm{Wm}^{-2}\right]$ & 16.0 & 19.1 & 45.7 & 17.3 & 22.4 & 40.9 & 14.3 & 17.4 & 30.9 \\
\hline$R^{2}$ & 0.97 & 0.95 & 0.95 & 0.98 & 0.96 & 0.94 & 0.98 & 0.97 & 0.98 \\
\hline $\mathrm{N}$ & 120 & 120 & 120 & 120 & 120 & 120 & 120 & 120 & 120 \\
\hline
\end{tabular}

\section{Discussion and conclusion}

The global radiation at surface calculated using look-up tables based on radiative transfer calculations with the 1D model Streamer are presented in comparison to a number of data products. Our method describes a technique to handle long-time datasets, like ISCCP Dx, with high temporal and spatial resolution. Uncertainties that become apparent in the evaluation with other datasets are caused by assumptions and simplifications using defined constants and increments for the look-up table to determine the shortwave and longwave radiant flux densities at TOA and at surface. Also data gaps and systematic gaps in the ISCCP Dx dataset intensify these incertitudes.

This study demonstrates the first version of our method that needs to be revised due to the extensive deviations to all compared datasets. The modification of the standardised atmospheric profiles included in Streamer is planned using the TIROS Operational Vertical Sounder (TOVS) atmospheric dataset (Kidwell, 1995). The variable integration of surface albedo for different land surfaces, mainly for vegetation with seasonal albedo variations, should be implemented. Besides the humidity depending on the five cloud classes and the atmospheric profiles has to be adjusted.

In general the global radiation exhibits on average higher values over the whole investigation area as well as for special regions than the products of comparison. Thus the comparison between the satellite data based products reveal mostly higher values with differences of $5-45 \mathrm{Wm}^{-2}$ $\left(\mathrm{RMSE}=17.7 \mathrm{Wm}^{-2}\right)$ to the SRB dataset and $5-35 \mathrm{Wm}^{-2}$ $\left(\mathrm{RMSE}=17.1 \mathrm{Wm}^{-2}\right)$ to the ISCCP FD dataset.

Surface measurements of global radiation for all available stations in Central Europe and in Germany reveal RMSEs of ca. $26 \mathrm{Wm}^{-2}$ in relation to our data and biases of ca. $20 \mathrm{Wm}^{-2}$. That causes a $10-12 \%$ higher amount of global radiation at surface for our method. But the comparison of point measurement versus area measurement is more difficult and hence associated with preassigned uncertainties.
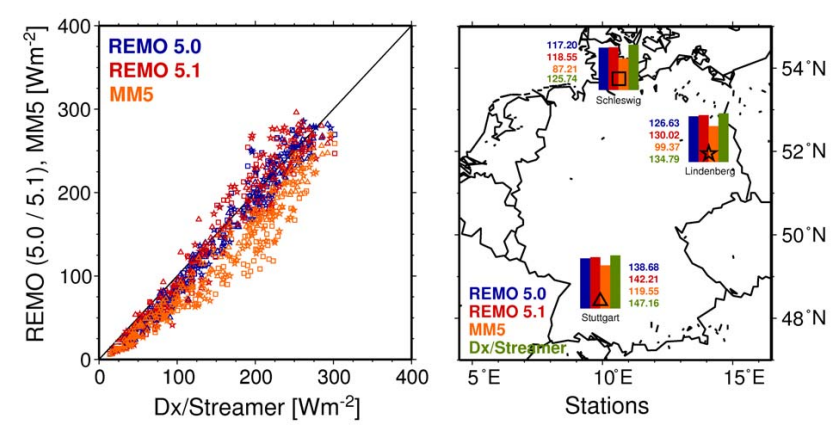

Fig. 9. Comparison of global radiation at surface (left: monthly values; right: 10-year means) for the regions Schleswig, Lindenberg and Stuttgart based on ISCCP Dx data (Dx/Streamer, green) and on the results of the regional climate models of the project partners (REMO 5.0 - BTU, blue; REMO 5.1 - MPI, red; MM5 - IFU, orange) over the period of 1984-1993.

The correction of the bias (approx. 10\%) between the Dx and the SRB dataset as well as between the Dx and the ISCCP FD dataset is carried out (Sommer, 2007 ${ }^{1}$ ). Accordingly not only the differences between the several grid cells could be reduced but also the corresponding RMSE values. They are now only one-third of the original values. This implicates lower deviations between Dx and SRB as well as between Dx and ISCCP FD than between the SRB and the ISCCP FD dataset (Sommer, 2007 ${ }^{1}$ ). It is difficult to realise this procedure in case of non-linear deviations. Hence it is more reasonable to improve the input for the look-up-table on the physical point of view.

As next step a better solution for replacing the gaps of the original ISCCP datasets and therefor reducing associated uncertainties are sought at present.

\footnotetext{
${ }^{1}$ Sommer, M.: Quantifizierung der räumlichen und zeitlichen Variabilitäten des Strahlungsflusses in Europa, Bestimmung mittels ISCCP Daten, Diss., TU Dresden, Institute of Hydrology and Meteorology, Department of Meteorology, submitted, 2007.
} 


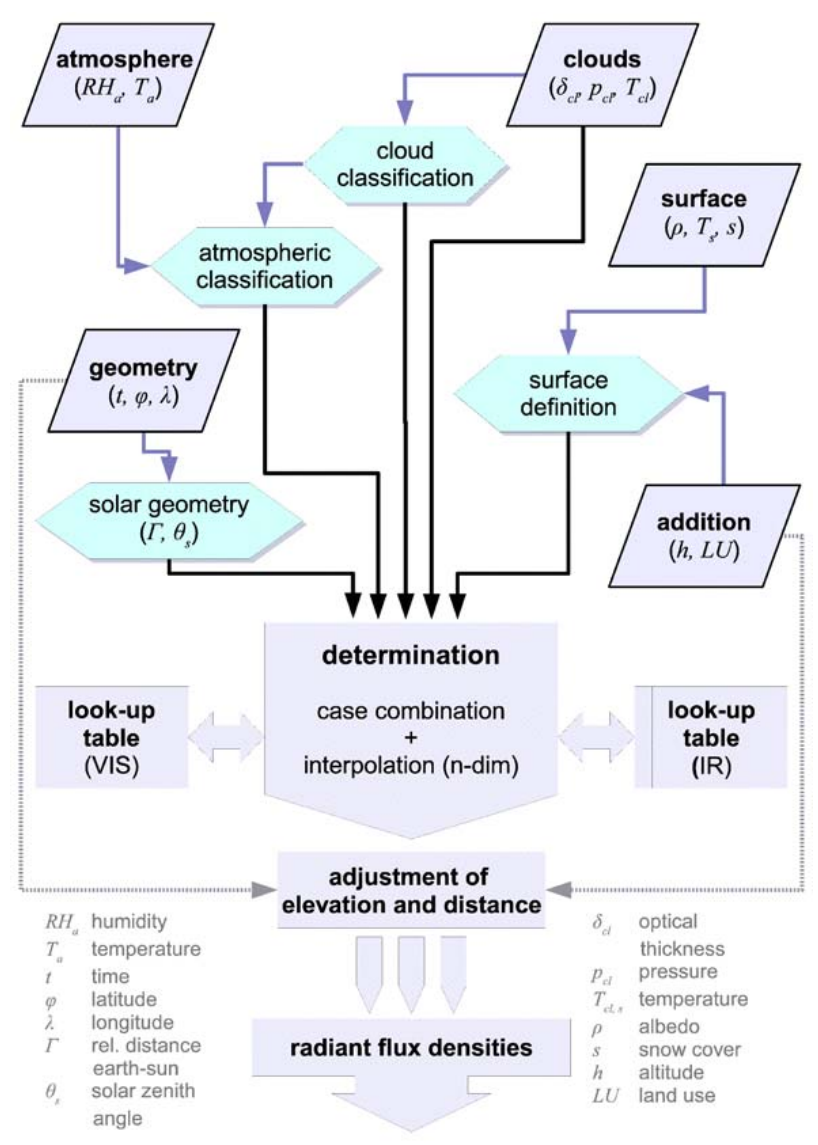

Fig. 10. Schematic diagram of the procedure to determine radiant flux densities using remote sensing data (ISCCP) (Sommer, 2007 ${ }^{1}$ ).

In spite of the demonstrated problems according the data basis and the used method the attained results are valuable because of their highly resolved spatial area-integrated information over a long investigation period. The produced radiant flux density datasets and especially the revised datasets are a solid basis for further improvements and investigations.

\section{Appendix A}

The newly developed method for the determination of radiant flux densities is based on a modular concept, where the core is the algorithm of determination coupled to the look-up tables.

The ten-dimensional look-up-tables consist of

- atmospheric parameters: standardised atmospheric profile, aerosol model, visibility, humidity

- cloud parameters: cloud class, optical thickness

- land surface parameters: land use, albedo, surface temperature and

- solar geometry: solar zenith angle.
Relevant nodes of these individual parameters have been defined in order to compute the shortwave and longwave radiant flux densities with Streamer for each parameter combination and its additional information, e.g. the $r_{e}$ or the LWC. All results together with their appropriate parameter sets have been tabulated separately for shortwave (VIS) and longwave (IR) radiant fluxes. Unrealistic and very unusual combinations have been filtered out.

Analyses of the ISCCP D datasets regarding the georeferencing, the gaps and the gap filling are made beforehand (Sommer, 2007 ${ }^{1}$ ).

The input dataset for each pixel of the time series consists of

- the geometry: date, longitude, latitude,

- the cloud properties: optical thickness, pressure, cloud top temperature

- the surface properties: albedo, temperature, snow cover

- the atmospheric properties: humidity, temperature profile and

- additional information: altitude, land use.

It is used to calculate the solar geometry, to define the surface type and to classify the clouds and the atmosphere. For each combination of the latter parameters the shortwave and longwave radiant flux densities can be determined using multidimensional linear interpolations between the nodes in the look-up tables (VIS/IR). The interpolations are carried out between $2^{n}$ nodes, where $n$ is the number of degrees of freedom (approx. 5-6 degrees of freedom are possible due to the direct coupling of dimensions).

At the end the adjustment of elevation and distance (Earth - Sun) is applied to the estimated shortwave and longwave radiant flux densities. For more details see Sommer (2007) ${ }^{1}$.

The schematic diagram for determination of radiant flux densities is shown in Fig. 10.

Look-up tables yield advantages in terms of reducing the computation time for complete time series of each pixel/grid cell due to the realisation of complex radiative transfer simulations only for relevant parameter combinations. The utilisation of the look-up tables is not only repeatable but also expandable and therefore applicable to different time periods and regions. 
Acknowledgements. The presented study was part of the research project Quantification of Uncertainties In Regional Climate and Climate Change Simulations (QUIRCS), funded within the German Climate Research Program (DEKLIM). We thank the NASA Langley Research Center Atmospheric Sciences Data Center for providing the ISCCP D data as well as the ISCCP FD and GEWEX SRB data. The surface radiation data (GEBA, DWD data) have been kindly provided by the ETH Zurich and the German Meteorological Service. We thank J. Key for providing the RTM Streamer. The authors wish to thank all involved persons for their help and for supplying model results.

Edited by: J. Quaas

\section{References}

Augustine, J. A., DeLuisi, J. J., and Long, C. N.: SURFRAD A National Surface Radiation Budget Network for Atmospheric research, B. Am. Meteorol. Soc., 81, 2341-2357, 2000.

Barkstrom, B., Harrison, E., Smith, G., Green, R., Kibler, J., Cess, R., and the ERBE Science Team: Earth Radiation Budget Experiment (ERBE) archival and April 1985 results, B. Am. Meteorol. Soc., 70, 1254-1262, 1989.

Cess, R. D., Zhang, M. H., Minnis, P., Corsetti, L., Dutton, E. G., Forgan, B. W., Garber, D. P., Gates, W. L., Hack, J. J., Harrison, E. F., Jing, X., Kiehi, J. T., Long, C. N., Morcrette, J.-J., Potter, G. L., Ramanathan, V., Subasilar, B., Whitlock, C. H., Young, D. F., and Zhou, Y.: Absorption of Solar Radiation by Clouds: Observations Versus Models, Science, 267, 496-499, doi:10.1126/science.267.5197.496, 1995.

Darnell, W. L., Staylor, W. F., Gupta, S. K., and Denn, F. M.: Estimation of Surface Insolation using sun-synchronous Satellite data, J. Climate, 1, 820-835, 1988.

Darnell, W. L., Staylor, W. F., Gupta, S. K., Ritchey, N. A., and Wilber, A. C.: Seasonal variation of surface radiation budget derived from International Satellite Cloud Climatology Project C1 data, J. Geophys. Res., 97, 15 741-15 760, 1992.

Evan, A. D., Heidinger, A. K., and Vimont, D. J.: Arguments against a physical long-term trend in global ISCCP cloud amounts, Geophys. Res. Lett., 34, L04701, doi:10.1029/2006GL028083, 2007.

Jacob, D. and Podzun, R.: Sensitivity studies with the regional climate model REMO, Meteorol. Atmos. Phys., 63, 119-129, 1997.

Jacob, D.: A note to the simulation of the annual and inter-annual variability of the water budget over the Baltic Sea drainage basin, Meteorol, Atmos. Phys., 77, 61-73, 2001.

Garrat, J. R.: Incoming Shortwave Fluxes at the Surface - A Comparison of GCM Results with Observations, J. Climate, 7, 72-80, 1994.

Gilgen, H., Wild, M., and Ohmura, A.: Global Energy Balance Archive (GEBA) Report 3: The GEBA Version 1995 Database, Zürcher Geographische Schriften 74, 105 pp. (available from Institute of Geography ETH, Winterthurerstr. 190, 8057 Zurich, Switzerland), 1997.

Gilgen, H. and Ohmura, A.: The Global Energy Balance Archive (GEBA), B. Am. Meteorol. Soc., 80, 831-850, 1999.

Grell, G. A., Dudhia, J., and Stauffer, D. R.: A description of the fifth generation Penn State/NCAR mesoscale model (MM5),
Technical report, National Centre for Atmospheric Research, Boulder, Colorado, USA, NCAR/TN-398+STR, 1995.

Grell, G. A., Schade, L., Knoche, R., Pfeiffer, A., and Egger, J.: Nonhydrostatic climate simulations over complex terrain, J. Geophys. Res., 105(D4), 29 595-29 608, 2000.

Gupta, S. K., Darnell, W. L., and Wilber, A. C.: A Parametrization for Longwave Surface Radiation from Satellite Data: Recent Improvements, J. Appl. Meteor., 31, 1361-1367, 1992.

Hollmann, R., Müller, R. W., and Gratzki, A.: CM-SAF surface radiation budget: First results with AVHRR data, Adv. Space Res., 37, 2166-2171, doi:10.1016/j.asr.2005.10.044, 2006.

Kidwell, K. B.: NOAA Polar Orbiter Data User Guide (TIROSN, NOAA-6, NOAA-7, NOAA-8, NOAA-9, NOAA-10, NOAA11, NOAA-12, NOAA-13 and NOAA-14), National Oceanic and Atmospheric Administration, National Environmental Satellite, Data and Information Service, Washingtion, DC, 394 pp., 1995.

Key, J. R.: Streamer Version 3.0 - User's Guide, NOAA/NESDIS, 70 pp., 2001.

Li, Z., Barker, H. W., and Moreau, L.: The Variable Effect of Clouds and Atmospheric Absorption of Solar Radiation, Nature, 376, 486-490, 1995.

McMillin, L. M.: Evaluation of a Classification Method for Retrieving Atmospheric Temperatures from Satellite Measurements, J. Appl. Meteorol., 30, 432-446, 1991.

Ohmura, A., Dutton, E. G., Forgan, B., and Co-Authors: Baseline Surface Radiation Network (BSRN/WCRP): New Precision Radiometry for Climate Research, B. Am. Meteorol. Soc., 79, 2115-2136, 1998.

Pinker, R. T. and Laszlo, I.: Modeling Surface Solar Irradiance for Satellite Applications on a Global Scale, J. Appl. Meteorol., 31, 194-211, 1992.

Pinker, R. T., Frouin, R., and Li, Z.: A Review of Satellite Methods to Derive Surface Shortwave Irradiance, Rem. Sens. Environ. 51, 108-124, 1995.

PRFI: Polar Radiation Fluxes from ISCCP (PRFI) - Procedure Description, http://stratus.ssec.wisc.edu/products/d1fluxes/fluxes3. html, 2000.

Rapp, J.: Konzeption, Problematik und Ergebnisse klimatologischer Trends für Europa und Deutschland, Berichte des Deutschen Wetterdienstes 212, Offenbach am Main, Selbstverlag des Deutschen Wetterdienstes, 2000.

Raschke, E., Ohmura, A., Rossow, W. B., Carlson, B. E., Zhang, Y. C., Stubenrauch, C., Kottek, M., and Wild, M.: Cloud Effects on the Radiation Budget Based on ISCCP Data (1991 to 1995), Int. J. Climotol., 25, 1103-1125, 2005.

Raschke, E., Bakan, S., and Kinne, S.: An assessment of radiation budget data provided by the ISCCP and GEWEX-SRB, Geophys. Res. Lett., 33, L07812, doi:10.1029/2005GL025503, 2006.

Rossow, W. B. and Schiffer, R. A.: ISCCP Cloud data Products, B. Am. Meteorol. Soc., 72, 2-20, 1991.

Rossow, W. B., Garder, L. C., Lu, P. J., and Walker, A. W.: International Satellite Cloud Climatology Project (ISCCP) Documentation of Cloud Data, WMO/TD-266, (revised), World Clim. Res. Progr. (ICSU and WMO), Geneva, 76 pp. plus three appendices, March 1991.

Rossow, W. B. and Zhang, Y. C.: Calculation of Surface and Top of Atmosphere Radiative Fluxes from Physical Quantities Based on ISCCP Data Sets, 2. Validation and first results, J. Geophys. Res., 100, 1167-1197, 1995. 
Rossow, W. B. and Zhang, Y. C.: Documentation of Radiative Flux Dataset (FC), http://isccp.giss.nasa.gov/docs/docs_fc.html, 1995.

Rossow, W. B., Walker, A. W., Beuschel, D. E., and Roiter, M. D.: International Satellite Cloud Climatology Project (ISCCP): Documentation of new cloud Datasets, WMO/TD-No. 737, World climate research Programme (ICSU and WMO), Genf, 1996.

Rossow, W. B. and Schiffer, R. A.: Advances in Understanding Clouds from ISCCP, B. Am. Meteorol. Soc., 80, 2261-2287, 1999.

Schiffer, R. A. and Rossow, W. B.: The International Satellite Cloud Climatology Project (ISCCP): The first project of the World Climate Research Programme, B. Am. Meteorol. Soc., 64, 779-984, 1983.

Stackhouse, P. W., Gupta, S. K., Cox, S. J., Chiacchio, M., and Mikovitz, J. C.: The WCRP/GEWEX Surface Radiation Budget Project Release 2: An assessment of surface fluxes at 1 degree resolution, 2000, in: Current Problems in Atmospheric Radiation, International Radiation Symposium, IRS 2000, edited by: Smith, W. L. and Timofeyev, Y. M., St. Petersburg, Russia, 2429 July 2000.

Stamnes, K., Tsay S. C., Wiscombe, W., and Jayaweera, K.: Numerically Stable Algorithm for Discrete-Ordinate-Method Radiative Transfer in Multiple Scattering and Emitting Layered Media, Appl. Opt., 27, 2502-2509, 1988.

Stokes, G. M. and Schwartz, S. E.: The Atmospheric Radiation Measurement (ARM) Program: Programmatic and Design of the Cloud and Radiation Test Bed, B. Am. Meteorol. Soc., 75, 12011221, 1994.
Toon, O. B., McKay C. P., and Ackermann, T. P.: Rapid Calculation of Radiative Heating Rates and Photodissociation Rates in Inhomogeneous Multiple Scattering Atmospheres, J. Geophys. Res., 94, 16 287-16301, 1989.

Wielicki, B. A., Barkstrom, B. R., Harrison, E. F., and Co-Authors: Clouds and the Earth's Radiant Energy System (CERES): Algorithm Overview, IEEE T. Geosci. Remote, 36, 1127-1141, 1998.

Wild, M., Gilgen, H., Roesch, A., Ohmura, A., Long, C. N., Dutton, E. G., Forgan, B., Kallis, A., Russak, V., Tsvetkov, A.: From Dimming to Brightening: Decadal Changes in Solar Radiation at Earth's Surface, Science, 308, 847-850, doi:10.1126/science.1103215, 2005.

Wild, M., Ohmura, A., Gilgen, H., and Roeckner, E.: Regional climate simulation with a high resolution GCM: surface radiation fluxes, Clim. Dynam., 11, 469-486, 1995.

Wild, M. and Liepert, B.: Excessive transmission of solar radiation through the cloud-free atmosphere in GCMs, Geophys. Res. Lett., 25, 2165-2168, 1998.

Zhang, Y. C., Rossow, W. B., and Lacis, A. A.: Calculation of Surface and Top of Atmosphere Radiative Fluxes from Physical Quantities Based on ISCCP Data Sets, 1. Method and Sensitivity to Input data Uncertainties, J. Geophys. Res., 100, 1149-1165, 1995. 